\title{
Analysis of the biodegradation of synthetic testosterone and 17 a-ethynylestradiol using the edible mushroom Lentinula edodes
}

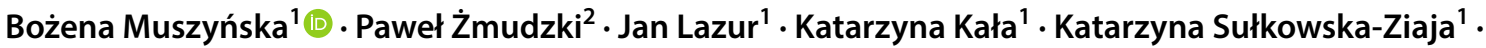 \\ Włodzimierz Opoka ${ }^{3}$
}

Received: 5 July 2018 / Accepted: 24 September 2018 / Published online: 28 September 2018

(c) The Author(s) 2018

\begin{abstract}
The mycelium of Lentinula edodes produces enzymes which may degrade xenobiotics including steroid hormones. The aim of the study was to determine whether the mycelium from in vitro cultures of $L$. edodes are able to degrade endocrine disruptors such as testosterone and $17 \alpha$-ethynylestradiol. To prove the possibility of xenobiotics degradation, cultures of $L$. edodes were cultivated in an Oddoux liquid medium with the addition of synthetic $17 \alpha$-ethynylestradiol and synthetic testosterone. The endocrine disruptors were extracted from the mycelium and determined qualitatively by RP-HPLC. The degradation products of testosterone and 17 $\alpha$-ethynylestradiol were identified using a UPLC/MS/MS analysis. Undegraded testosterone was determined at the amount of $2.97 \mathrm{mg} / \mathrm{g}$ dry weight but only in one of the $L$. edodes extracts from in vitro cultures supplemented with $50 \mathrm{mg}$ of this compound. In turn, 17 $\alpha$-ethynylestradiol was not determined in any samples. Additionally in all extracts, mushroom sterols (ergosterol peroxide and ergosterol) were determined. Their total amounts were significantly lower in samples containing the abovementioned steroids than in extracts from mycelium L. edodes without the addition of steroid hormones. The results demonstrated that the mycelium of $L$. edodes can be used in the biodegradation process of a water environment contaminated with endocrine disruptors.
\end{abstract}

Keywords Biodegradation $\cdot$ Edible mushrooms $\cdot 17 \alpha$-Ethynylestradiol $\cdot$ Lentinula edodes $\cdot$ Testosterone

\section{Introduction}

Environmental pollution with xenobiotics (including steroid hormones) has become a serious problem on a global scale. This problem could be solved using white rot fungi (WRF), represented by Lentinula edodes. The species has

Electronic supplementary material The online version of this article (https://doi.org/10.1007/s13205-018-1458-x) contains supplementary material, which is available to authorized users.

Bożena Muszyńska

muchon@poczta.fm

1 Department of Pharmaceutical Botany, Faculty of Pharmacy, Jagiellonian University Medical College, 30-688 Kraków, Poland

2 Department of Medicinal Chemistry, Faculty of Pharmacy, Jagiellonian University Medical College, 30-688 Kraków, Poland

3 Department of Inorganic and Analytical Chemistry, Faculty of Pharmacy, Jagiellonian University Medical College, 30-688 Kraków, Poland been extensively studied, because its fruiting bodies contain compounds exhibiting anticancer, antioxidant, and antimicrobial effects (Braga 2011; Mleczek et al. 2017; Muszyńska et al. 2017).

Moreover, the mycelium of $L$. edodes produces enzymes with oxidative effects, which may degrade xenobiotics (Kryczyk et al. 2017). White rot mushrooms can transform durable contaminants such as polycyclic aromatic carbohydrates (Lang et al. 1995). These properties can also be used to treat soil contaminated with petroleum. WRF are also efficient in the biodegradation of soils contaminated especially with heavy metals, owing to their capacity to accumulate such metals in the fruiting bodies (Cerniglia et al. 1992; Lang et al. 1995). The efficiency of mushrooms in biodegradation processes is further caused by their rapid growth, production of large amounts of biomass and the widespread occurrence of hyphae in the soil (Ashoka et al. 2002; Wong 2009).

The most important mechanism for the decomposition of xenobiotics by mushroom enzymes is related to the decomposition of lignin. Extracellular enzymes modifying lignin possess low substrate specificity; thus, they can decompose 
large amounts of highly resistant organic contaminants with a structure similar to that of lignin (Dąbrowska et al. 2018; Mansur et al. 2003). The major enzymes of the lignin degradation system are lignin peroxidase, laccase, manganese-dependent peroxidase, and enzymes producing $\mathrm{H}_{2} \mathrm{O}_{2}$, although not all ligninolytic fungi synthesize them to the same degree (Hofrichter 2002; Kirk and Farrell 1987). Mushroom laccase has been proved able to degrade many pharmaceuticals (for example: naproxen, ketoprofen, diclofenac) (Taheran et al. 2016).

There are numerous sources of environmental contamination by endocrine disruptors. In stock breeding, steroid hormones are used to increase feeding and muscle growth efficiency. The so-called concentrated animal feeding operations (CAFOs) pose a risk to the environment. The feed used in this animal feeding method contains synthetic steroids, which are excreted with their excrements and then leached into water, including groundwater (Anderson et al. 2012). Estrogen has been determined in the excrements and the solid waste of animals and in fertilizers used directly on arable fields (Biswas et al. 2013). Livestock excrements are probably the greatest source of estrogen in the environment. Based on the literature data, pregnant women excrete 260-790 and 280-600 $\mu \mathrm{g}$ /day of estrone and estradiol, respectively. These values are considerably higher than in the case of postmenopausal women treated with hormone replacement therapy (HRT) (Hotchkiss et al. 2008). Additionally, steroid hormones are currently overused by a large group of persons to build their muscle mass. Moreover, hospitals constitute another source of estrogen contamination. Several experiments have corroborated the fact that estrogen, with particularly high levels of estriol, has been determined in samples of hospital sewage (Arnold et al. 2014; Avberšek et al. 2011).

These hormones may contribute to the development of cardiovascular diseases and even cancers (Ibarluzea et al. 2004; Liang and Shan 2013; Moore et al. 2016; Salla et al. 2016). Unfortunately, municipal water treatment plants are not efficient in the removal of steroid hormones from wastewater, thus allowing them to be directly released into the environment (Andaluri et al. 2013; El Osta et al. 2016; Hotchkiss et al. 2008). Removal of endocrine disrupting compounds with WRF was reported (Cruz-Morató et al. 2014).

Therefore, the search for a safe and efficient agent for biodegradation has emerged as an important task. The present study is aimed at the determination (with the use of analytical methods such as RP-HPLC chromatography) of whether L. edodes, degrades endocrine disruptors such as $17 \alpha$-ethynylestradiol and testosterone under in vitro culture conditions.

The degradation products of testosterone and $17 \alpha$-ethynylestradiol were identified using an UPLC/MS analysis and fragmentation patterns obtained from MS/MS experiments.

\section{Materials and methods}

\section{Mushroom cultures and reagents}

For the experiments, the fruiting bodies of Lentinula edodes (Berk.) Pegler of commercial origin, purchased at a local supermarket (2016), were used. The taxonomic identification was based on MycoKey 4.1 software (http://www. mycokey.com) by Muszyńska. Representative samples of the material used for the studies were kept at the Department of Pharmaceutical Botany, Jagiellonian University Medical College (Kraków, Poland).

Some of the young sporocarps of L. edodes were used to develop in vitro cultures, in which the obtained mycelium formed the material for further analysis. The explants were degreased with $70 \%$ ethanol for $15 \mathrm{~s}$, followed by $0.5 \mathrm{~min}$ sterilization in $15 \%$ sodium hypochlorite. After repeated washing with sterile redistilled water, the clear fragments of the fruiting bodies were transferred to a solid agar-solidified Oddoux medium (laminar airflow). Cultures from the solid medium were used to establish experimental cultures cultivated on the modified liquid Oddoux medium. The initial inoculum from the solid medium was $0.1 \mathrm{~g}$. The cultures were shaken at the rate of $140 \mathrm{rpm}$ (shaker ALTEL, Poland). They were then incubated at $25^{\circ} \mathrm{C} \pm 2{ }^{\circ} \mathrm{C}$ under a photoperiod (10-h light, 900 lx, and 14-h dark). The agitated liquid cultures of $L$. edodes were maintained for 3 weeks and then subcultured.

Standard substances of testosterone, $17 \alpha$-ethynylestradiol, ergosterol, ergosterol peroxide, glucose, along with maltose extract, casein hydrolysate, $\mathrm{B}_{1}$ and $\mathrm{B}_{6}$ vitamins, L-asparagine, adenine, yeast extract, and agar were purchased from Sigma-Aldrich (St. Louis, MO, USA). The chemicals $\mathrm{MgSO}_{4} \cdot 7 \mathrm{H}_{2} \mathrm{O}, \mathrm{NH}_{4} \mathrm{Cl}, \mathrm{KH}_{2} \mathrm{PO}_{4}, \mathrm{FeCl}_{3}, \mathrm{MnSO}_{4} \cdot \mathrm{H}_{2} \mathrm{O}$, $\mathrm{ZnSO}_{4} \cdot 7 \mathrm{H}_{2} \mathrm{O}$, and $\mathrm{CaCl}_{2} \cdot 6 \mathrm{H}_{2} \mathrm{O}$ were purchased from $\mathrm{PPH}$ Golpharm (Kraków, Poland). HPLC-grade methanol, acetonitrile, and formic acid were purchased from Merck (Darmstadt, Germany). Water (quadruple-distilled) with a conductivity of less than $1 \mu \mathrm{S} \mathrm{cm}^{-1}$ was obtained using an S2-97A2 distillation apparatus (ChemLand, Stargard, Poland).

\section{Mushroom biomass production and degradation studies}

The mycelium of $L$. edodes was passaged in previously prepared flasks, each containing $250 \mathrm{~mL}$ of the 
Oddoux liquid medium. The following amounts of $17 \alpha$-ethynylestradiol were added to the medium: 100 and $200 \mu \mathrm{g}$ per $250 \mathrm{~mL}$; those of testosterone were as follows: 25 and $50 \mathrm{mg} / 250 \mathrm{~mL}$ of the medium. Following dissolution in a small volume of ethyl alcohol, the steroids were quantitatively transferred under sterile conditions to flasks containing in vitro cultures of L. edodes. Moreover, a control sample was prepared without the addition of steroids. The flasks were placed on an Altel rotary shaker operating at $140 \mathrm{rpm}$.

After 21 days of the in vitro cultures of $L$. edodes, the biomass was separated from the medium by rinsing with redistilled water. Subsequently, the obtained mycelium and the post-culture media were subjected to lyophilization (Freezone 4.5 lyophilizer by Labconco).

\section{Extraction, separation and quantification of steroid hormones}

Five grams of powdered materials were extracted (mycelium from the in vitro cultures in the media containing endocrine disruptors and the post-culture media) with a mixture of methanol and dichloromethane at a 75:25 (v/v) ratio in an ultrasonic bath at the frequency of $49 \mathrm{kHz}$ for $30 \mathrm{~min}$ (Sonic-2, Polsonic). The merged extracts $(300 \mathrm{~mL}$ ) were concentrated to dryness using a rotary vacuum evaporator at $22{ }^{\circ} \mathrm{C} \pm 2{ }^{\circ} \mathrm{C}$ and then subjected to RP-HPLC and UPLC/MS/MS analyses. The identity and the amounts of the steroid hormones in the obtained extracts were identified by DAD-HPLC (according to Yuan et al. 2008). The details of the DAD-HPLC analysis, equipment, and conditions were the same as those described by SułkowskaZiaja et al. (2015). The quantitative analyses used the standards: testosterone and $17 \alpha$-ethynylestradiol from Sigma-Aldrich Co. The quantitative analyses were performed using a calibration curve based on the assumption of a linear relationship between the size of the field under the peak and the concentration of the standard substance. Standard substances (by Sigma-Aldrich), testosterone and $17 \alpha$-ethynylestradiol, were dissolved in a mixture of methanol and dichloromethane (75:25 (v/v)). Solutions with the following concentrations were prepared for testosterone: $1 \mathrm{mg} / \mathrm{mL}, 0.5 \mathrm{mg} / \mathrm{mL}, 0.25 \mathrm{mg} / \mathrm{mL}, 0.125 \mathrm{mg} /$ $\mathrm{mL}$, and $0.0625 \mathrm{mg} / \mathrm{L}$. Further, solutions with the following concentrations were prepared for $17 \alpha$-ethynylestradiol: $0.25 \mathrm{mg} / \mathrm{mL}, 0.125 \mathrm{mg} / \mathrm{mL}, 0.0625 \mathrm{mg} / \mathrm{mL}, 0.0313 \mathrm{mg} /$ $\mathrm{mL}$, and $0.0156 \mathrm{mg} / \mathrm{mL}$. To determine the possibility of whether the added hormones affect the level of steroids that occur naturally in the fruiting bodies of L. edodes (ergosterol, ergosterol peroxide), calibration curves were drawn for these compounds using the following concentrations: $0.5,0.25,0.125,0.0625$, and $0.03125 \mathrm{mg} / \mathrm{mL}$.

\section{UPLC/MS/MS analysis}

A Waters ACQUITY ${ }^{\circledR}$ UPLC $^{\circledR}$ from Waters Corporation (Milford, MA, USA) combined with a Waters TQD mass spectrometer were used to perform UPLC-MS/MS analysis. An Acquity UPLC BEH (bridged ethyl hybrid) $\mathrm{C}_{18}$ column equipped with an Acquity UPLC BEH $\mathrm{C}_{18}$ VanGuard precolumn were used to perform chromatographic separations. The column was maintained under the required conditions. A Waters e $\lambda$ PDA detector was used to obtain chromatograms. The detailed UPLC-MS/MS analysis was carried out strictly in accordance with the methodology presented by Dąbrowska et al. (2018).

\section{Statistical analysis}

Samples were determined in duplicate. Data were presented as means and standard deviations (SD). The statistical analysis was accomplished using one-way ANOVA followed by a post hoc Tukey test. A $p$ value of less than 0.05 was considered significant.

\section{Results and discussion}

Good biomass growth for L. edodes was obtained in the liquid cultures on the modified Oddoux medium and on the media containing testosterone and $17 \alpha$-ethynylestradiol. The dynamics of the mycelium growth in the liquid Oddoux medium did not differ from those registered in earlier studies; however, upon the addition of endocrine disruptors, the growth rate increased twofold (Muszyńska et al. 2013).

The results obtained from the determinations using RPHPLC for the contents of the steroid compounds in the mycelium extracts from the in vitro cultures in media containing testosterone and $17 \alpha$-ethynylestradiol and the postculture media are presented in Table 1 .

The concentrations of $17 \alpha$-ethynylestradiol and testosterone used in the experiments as additives to the mycelial cultures of $L$. edodes typically corresponded to the doses of these hormones normally used by patients (17 $\alpha$-ethynylestradiol: 100 and $200 \mu \mathrm{g} / 250 \mathrm{~mL}$; testosterone: 25 and $50 \mathrm{mg} / 250 \mathrm{~mL}$ of the medium). The presented experiment demonstrated the capacity of in vitro cultures of L. edodes to degrade $17 \alpha$-ethynylestradiol and testosterone. None of the extracts from the mycelium from in vitro cultures in media containing $17 \alpha$-ethynylestradiol or the postculture media were found to contain $17 \alpha$-ethynylestradiol. In the case of the extracts from the mycelium and the postculture media of $L$. edodes from in vitro cultures incubated with testosterone, total biodegradation occurred solely in those cultures in medium containing $25 \mathrm{mg} / 250 \mathrm{~mL}$ of the 


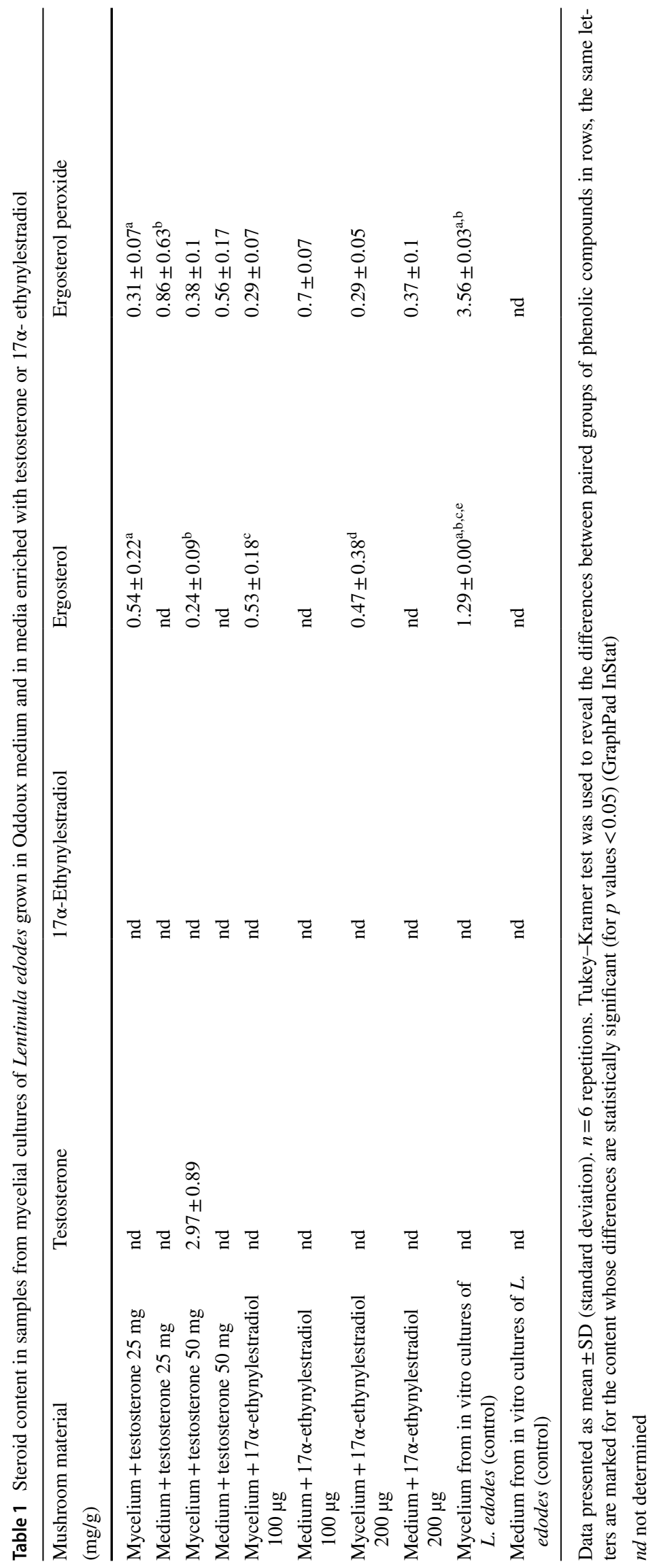


Table 2 Proposed structures of the biodegradation products of testosterone

\begin{tabular}{|c|c|c|c|c|}
\hline Compound & $\begin{array}{c}\mathrm{RT} \\
(\mathrm{min})\end{array}$ & {$\left[\mathrm{M}+\mathrm{H}^{+}\right]$} & Fragmentation ions & Structure \\
\hline TP-1 & 2.10 & 229.2 & $105.1,131.1,161.1,181.1,201.1$ & \\
\hline TP-2 & 2.19 & 213.1 & $93.0,109.1,189.1$ & \\
\hline TP-3 & 2.24 & 261.2 & $109.1,135.1,153.1,197.1,229.2$ & \\
\hline TP-4 & 2.38 & 197.1 & $153.1,169.1,179.1$ & \\
\hline TP-5 & 2.74 & 213.1 & $93.1,109.1,123.1,151.1,195.1$ & \\
\hline $\begin{array}{l}\text { TP-6 } \\
\text { TP-7 }\end{array}$ & $\begin{array}{l}2.85 \\
2.88\end{array}$ & 321.2 & $\begin{array}{l}107.1,121.1,145.1,213.2,239.2 \\
241.2,259.2,267.2,285.2,303.2\end{array}$ & \\
\hline TP-8 & 2.94 & 211.1 & $69.0,107.0,133.1,155.1,183.1$ & \\
\hline TP-9 & 3.07 & 321.2 & $\begin{array}{c}29.1,143.1,175.1,199.1,225.2 \\
257.2,267.2,285.2,303.2\end{array}$ & \\
\hline ТP-10 & 3.50 & 321.2 & $\begin{array}{c}129.1,143.1,175.1,199.1,225.2 \\
257.2,267.2,285.2,303.2\end{array}$ & \\
\hline
\end{tabular}

hormone. The testosterone content was determined to be, on average, $2.97 \mathrm{mg} / \mathrm{g} \mathrm{d}$.w., and only in the mycelium from the in vitro cultures of $L$. edodes enriched with the addition of testosterone was the content $50 \mathrm{mg} / 250 \mathrm{~mL}$ of the medium.

The experiments demonstrated that the mycelium of $L$. edodes resulted in the decomposition of the endocrine disruptors: $17 \alpha$-ethynylestradiol and testosterone.

The ligninolytic enzymes produced by L. edodes exhibited oxidative properties and were responsible for the degradation of the tested hormones in the in vitro cultures. The degradation of $17 \alpha$-ethynylestradiol was observed in the experiments of Eldridge et al. (2017) and Riggins and Gregory (2015). The supplementation of L. edodes in the in vitro cultures with compounds increasing the production of laccase increased the rate of $17 \alpha$-ethynylestradiol degradation. Moreover, the main product determined in both the mass spectra was hydroxylated $17 \alpha$-ethynylestradiol. The results obtained by the abovementioned authors confirmed that laccase contributes to the degradation of 
Table 2 (continued)

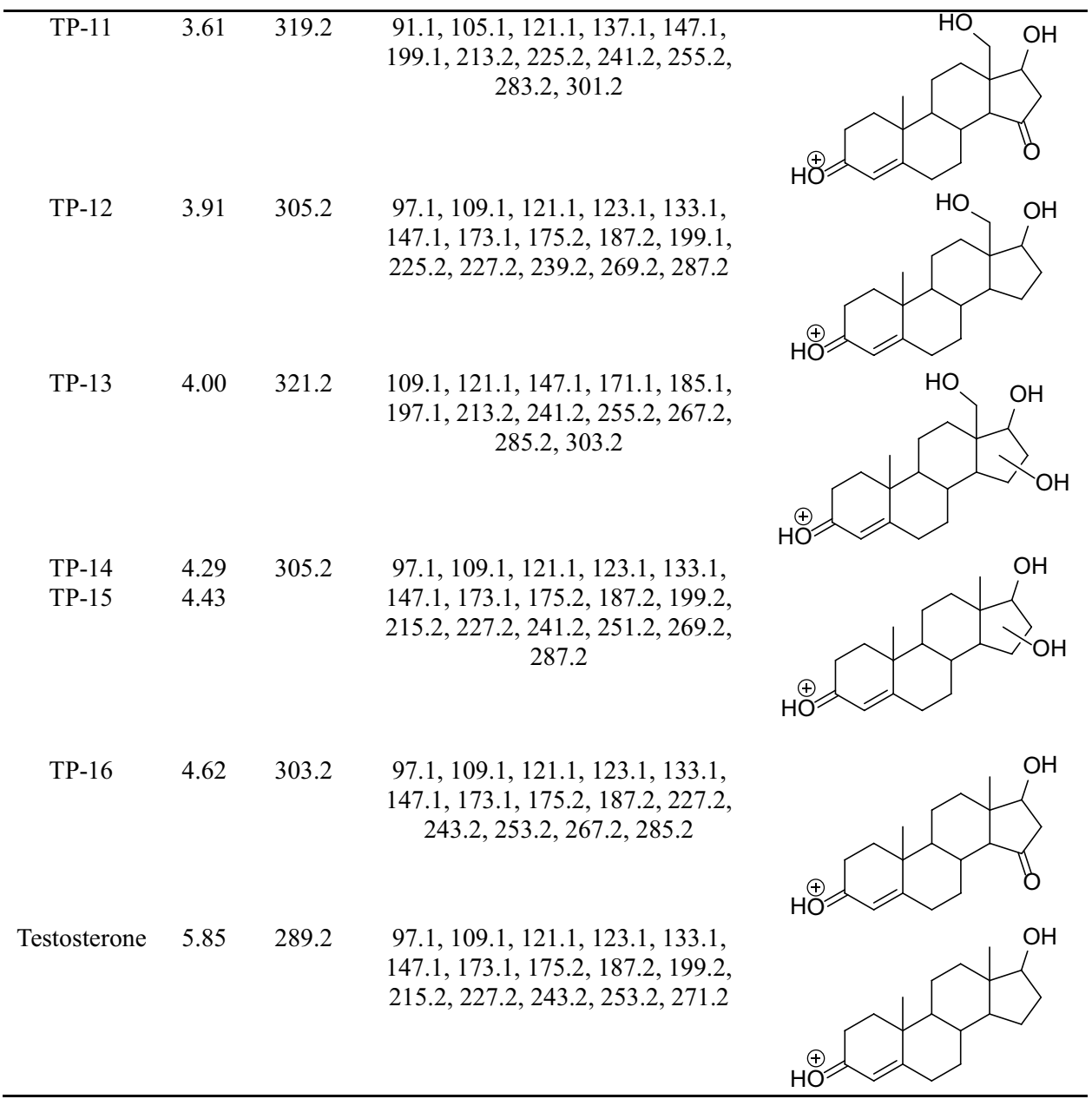

$17 \alpha$-ethynylestradiol (Eldridge et al. 2017; Riggins and Gregory 2015).

Furthermore, the current study included an analysis of the biodegradation products obtained in the cases of endocrine disruptors added to the mycelium.

An analysis of the extracts of the pure medium and of the mushroom mycelium without the added testosterone and $17 \alpha$-ethynylestradiol showed no peaks on the UV chromatogram; thus, all of the compounds observed on the chromatograms of the extracts of the mushroom materials with the added steroids were most probably products of their biodegradation.

The degradation products of testosterone and $17 \alpha$-ethynylestradiol were identified using an UPLC/MS analysis and fragmentation patterns obtained from MS/MS experiments. The proposed structures of the degradation products for testosterone are shown in Table 2 and for $17 \alpha$-ethynylestradiol in Table 3 . The proposed fragmentation patterns of testosterone and $17 \alpha$-ethynylestradiol are presented schematically in Table 4.

The degradation process was found to primarily affect rings $\mathrm{C}$ and $\mathrm{D}$ of the steroids, leading to their oxidation and cleavage. Additionally, the oxidation of ring $\mathrm{B}$ was observed, and to a lesser extent, that of ring A. The degradation process was considerably more effective for $17 \alpha$-ethynylestradiol, for which only a small amount of compounds were found with the remaining $\mathrm{A}$ and $\mathrm{B}$ rings and only one compound possessing rings $\mathrm{A}-\mathrm{C}$. In the case of testosterone, the degradation process was less effective and all of the compounds observed in the extracts from the cultures retained rings $\mathrm{A}-\mathrm{D}$ or $\mathrm{A}-\mathrm{C}$.

No major differences were observed in the degradation products ratios between the samples from the cultures with different amounts of the steroids.

The experiments further determined the level of ergosterol and ergosterol peroxide. None of the tested steroid compounds were found in the extracts from the medium used for in vitro cultures of L. edodes (control). Ergosterol 
Table 3 Proposed structures of the biodegradation products of $17 \alpha$-ethynylestradiol

\begin{tabular}{|c|c|c|c|c|}
\hline Compound & $\begin{array}{c}\mathrm{RT} \\
(\mathrm{min})\end{array}$ & {$\left[\mathrm{M}+\mathrm{H}^{+}\right]$} & Fragmentation ions & Structure \\
\hline EP-1 & 2.10 & 205.1 & $119.0,145.1,159.1,187.1$ & \\
\hline EP-2 & 2.19 & 213.1 & $93.0,119.0,133.1,151.1,169.1$ & \\
\hline EP-3 & 2.24 & 261.1 & $95.0,131.1,163.1,215.1,243.1$ & \\
\hline EP-4 & 2.39 & 197.1 & $97.1,121.1,139.1,169.1$ & \\
\hline EP-5 & 2.40 & 217.0 & $81.0,131.0,143.0,171.0,189.1$ & \\
\hline EP-6 & 2.74 & 213.1 & $\begin{array}{c}69.0,93.0,107.0,125.1,153.1 \\
169.1,195.1\end{array}$ & \\
\hline EP-7 & 2.77 & 243.1 & $\begin{array}{c}81.0,95.0,125.0,133.0,167.0 \\
211.1\end{array}$ & \\
\hline EP-8 & 2.89 & 169.1 & $69.0,93.0,107.0,125.1,153.1$ & \\
\hline EP-9 & 2.95 & 211 & $69.0,97.0,153.1,193.1$ & \\
\hline
\end{tabular}

was determined solely in mycelium. Ergosterol and ergosterol peroxide occur in a majority of representatives of Basidiomycota species. The mean ergosterol content in the fruiting bodies of genus Lactarius is $2.69-3.00 \mathrm{mg} / \mathrm{g}$ d.w. and in Cantharellus 3.04-3.77 mg/g d.w. In turn in mycelial cultures of Sarcodon imbricatus amounts of ergosterol and ergosterol peroxide were $1.97 \mathrm{mg} / \mathrm{g} \mathrm{d} . \mathrm{w}$. and $2.00 \mathrm{mg} / \mathrm{g} \mathrm{d.w.,} \mathrm{respectively} \mathrm{(Sułkowska-Ziaja} \mathrm{et} \mathrm{al.}$ 2016). It was proven that these compounds are essential for the normal development of hyphae of higher fungi while ergosterol is the main part of fungal cell membranes. Although it occurs in a majority of Basidiomycota species, 
Table 4 Proposed fragmentation pattern of testosterone and $17 \alpha$-ethynylestradiol

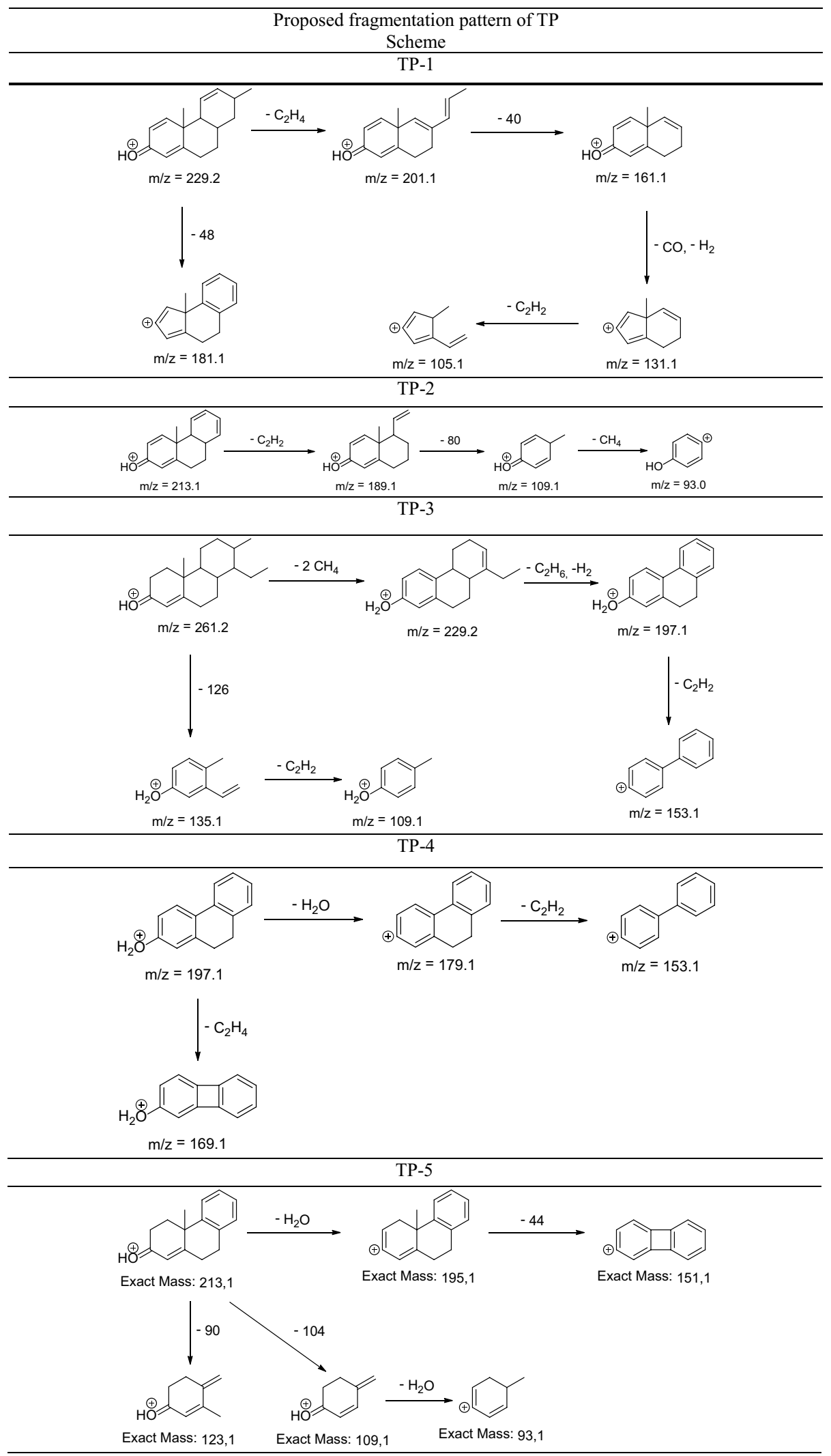


Table 4 (continued)

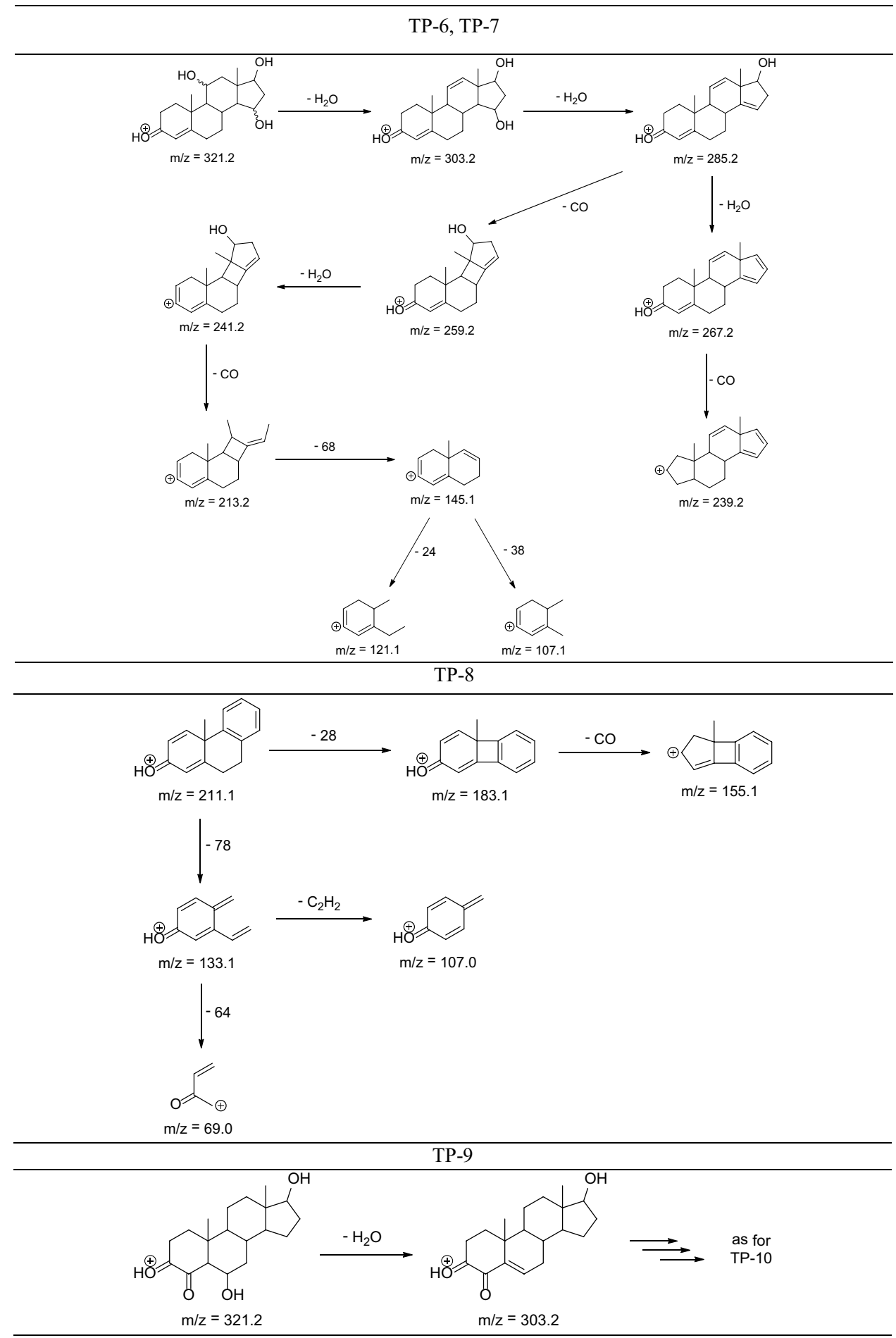

the highest content of this compound was noted in saprophytic fungi (Brennan et al. 1975). We found that the extract from the $L$. edodes mycelium contained a higher amount (3.65 mg/g d.w.) of ergosterol peroxide than that of ergosterol ( $1.29 \mathrm{mg} / \mathrm{g}$ d.w.). Further, the addition of testosterone and $17 \alpha$-ethynylestradiol to the culture medium resulted in a reduction of the ergosterol and ergosterol peroxide production by the mycelium of the studied species. The ergosterol content in the extracts from the L. edodes mycelium from cultures without the addition of endocrine disruptors was, on average, $65.5 \%$ higher than in the extracts from the mycelium of the experimental cultures. Moreover, the mycelium extracts contained an average of $91.08 \%$ more ergosterol peroxide than the extracts from the L.edodes 
Table 4 (continued)

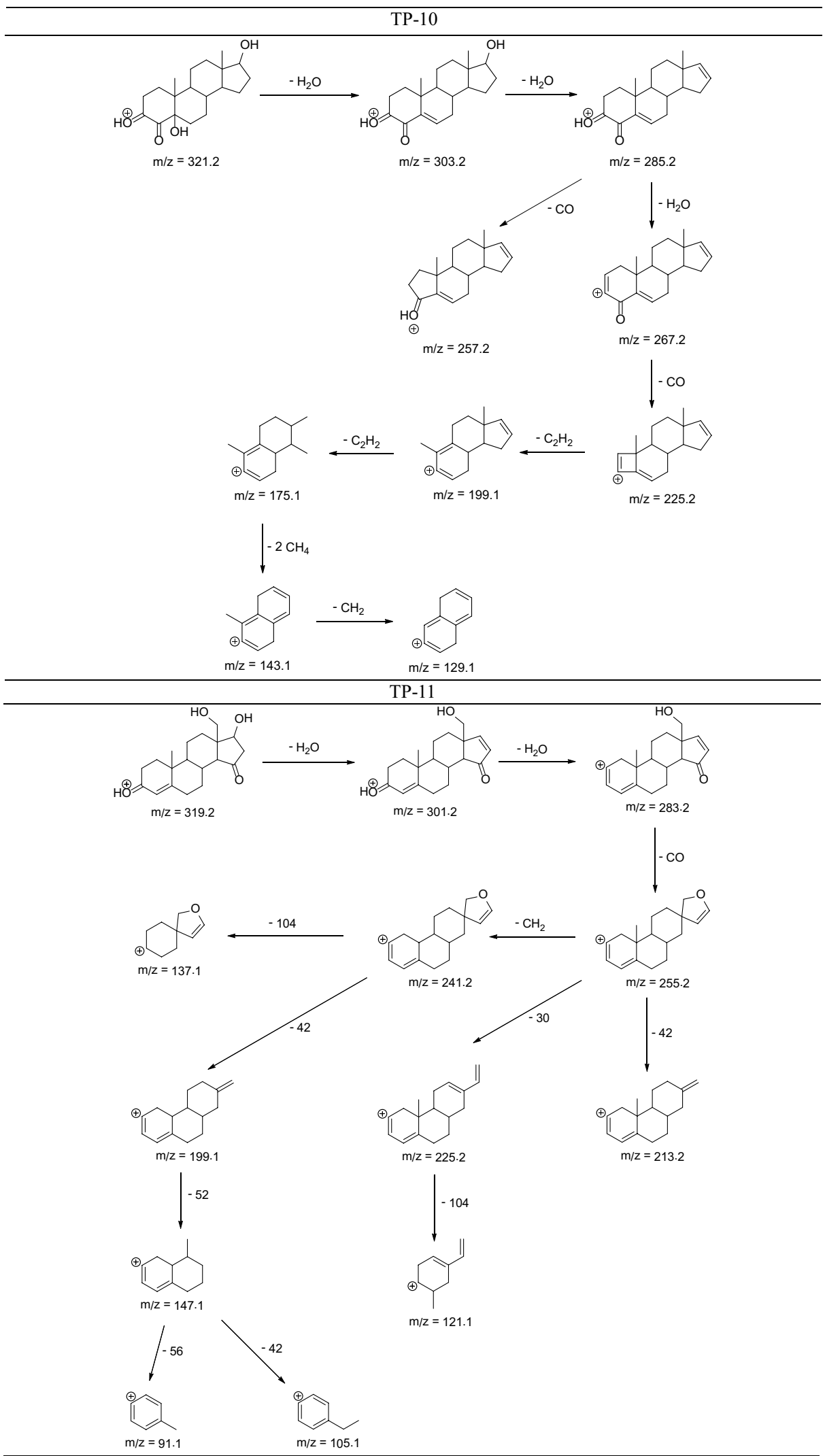


Table 4 (continued)

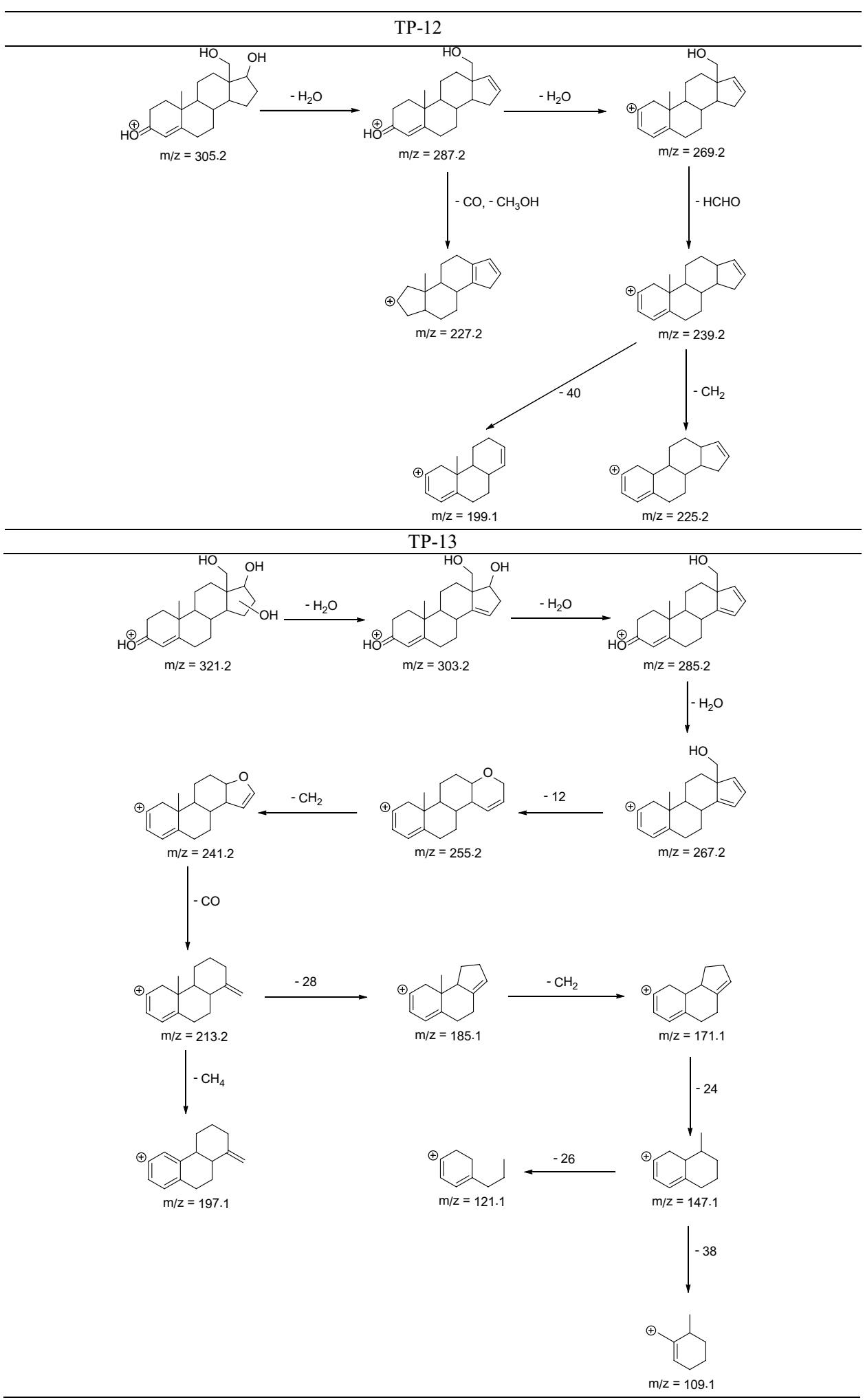

mycelium from those cultures enriched with testosterone and $17 \alpha$-ethynylestradiol.
The experiment showed that the addition of synthetic steroids influenced the inhibition of the synthesis of endogenous metabolites, such as ergosterol and ergosterol peroxide. 
Table 4 (continued)

TP-14, TP-15

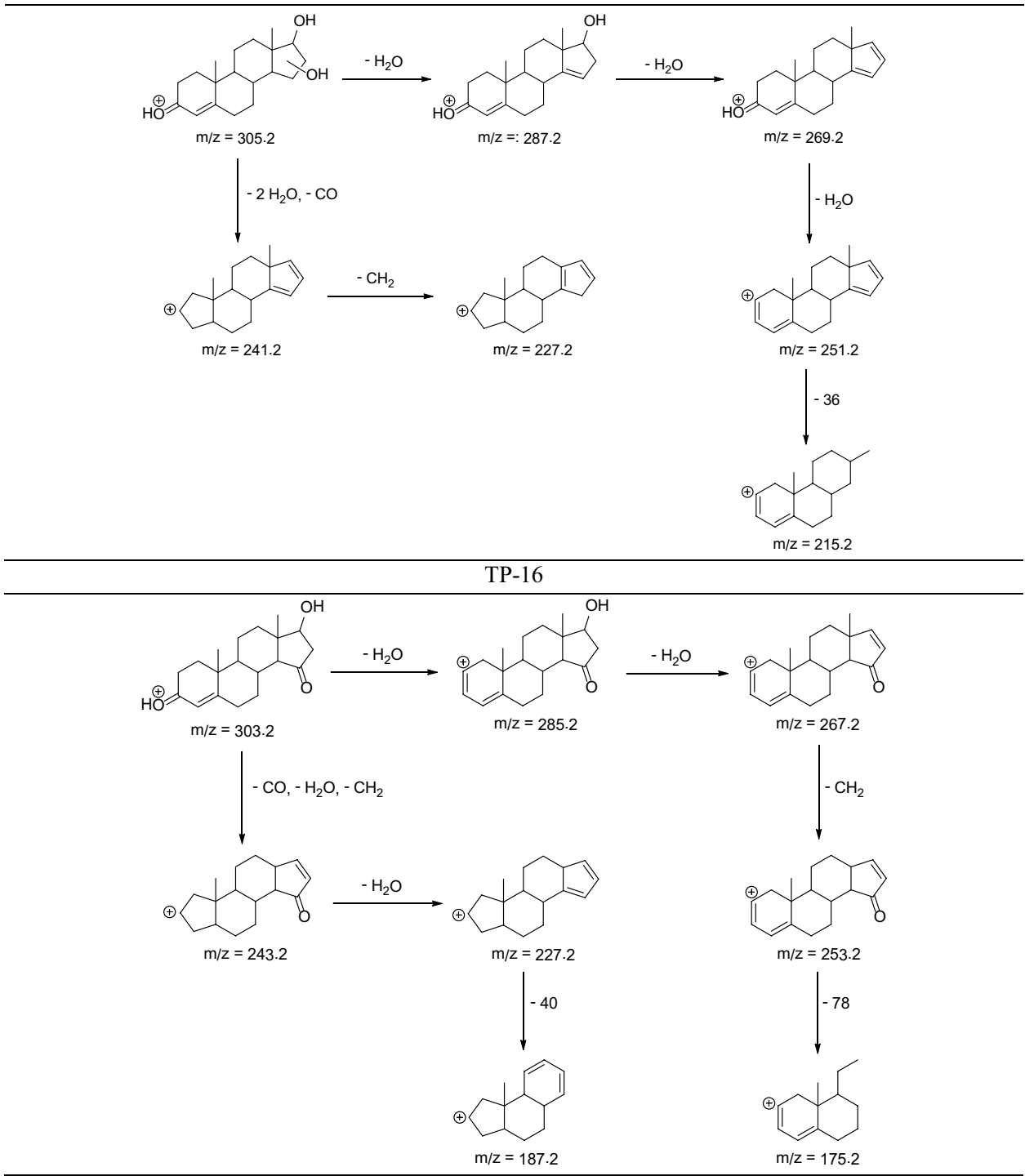

\section{Conclusions}

Endocrine disruptors such as $17 \alpha$-ethynylestradiol and testosterone, even at concentrations of nanograms per liter, disturb the functioning of the hormone system of vertebrates; therefore, their biodegradation is necessary. The search for new technologies for treating water containing compounds that disturb the action of the hormone system is an important task and, as demonstrated by the present study, the L. edodes mycelium may be of use for this purpose.
Steroids in the environment can potentially create persistent toxins. The above-discussed preliminary tests have shown that the examined $L$. edodes mycelia require only a short time period to remove testosterone and 17 $\alpha$-ethynylestradiol from the medium, and thus, mycodegradation can be used as an alternative to the other methods of the biodegradation of steroids compounds contaminating the environment, particularly water. 
Table 4 (continued)
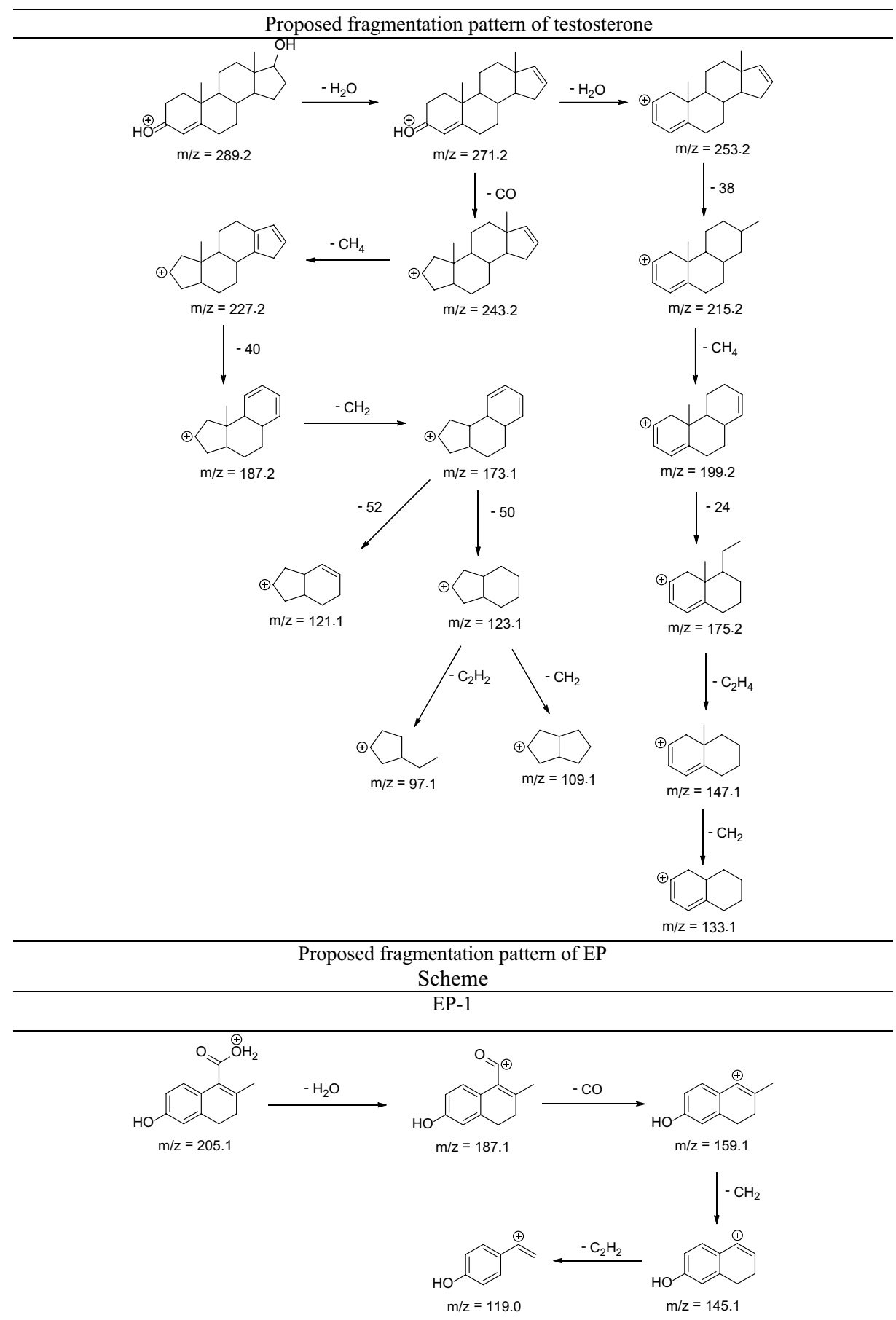

EP-2

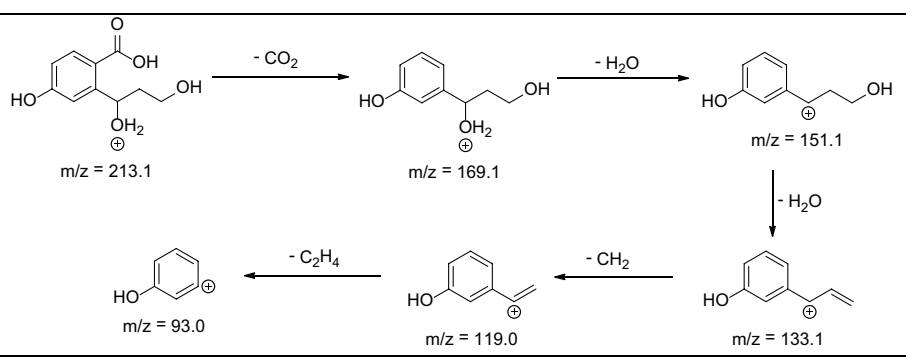


Table 4 (continued)

EP-3

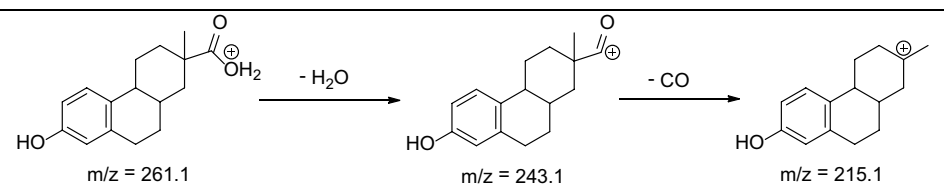

(-<smiles>COc1ccc2c(c1)CCCC2C</smiles>

$\mathrm{m} / \mathrm{z}=163.1$

$-68$

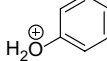

$\mathrm{m} / \mathrm{z}=95.0$

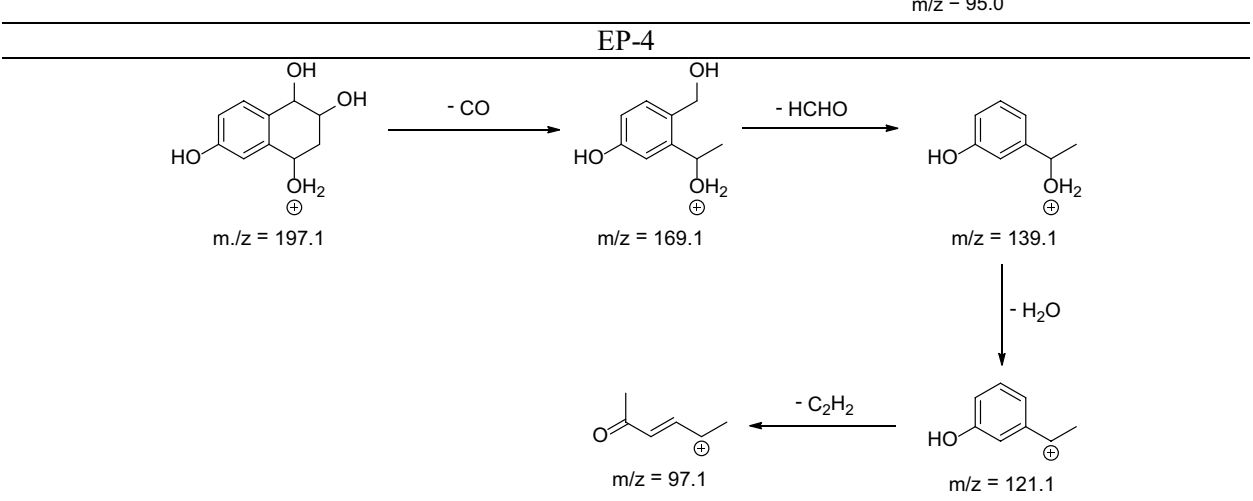

\section{EP-5}

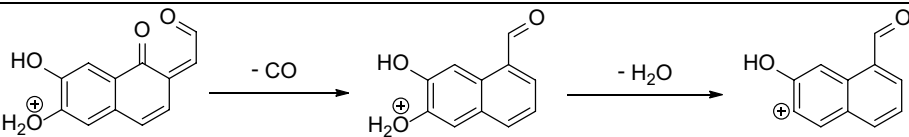

$\mathrm{m} / \mathrm{z}=217.0$

$\mathrm{m} / \mathrm{z}=189.1$

$\mathrm{m} / \mathrm{z}=171.0$

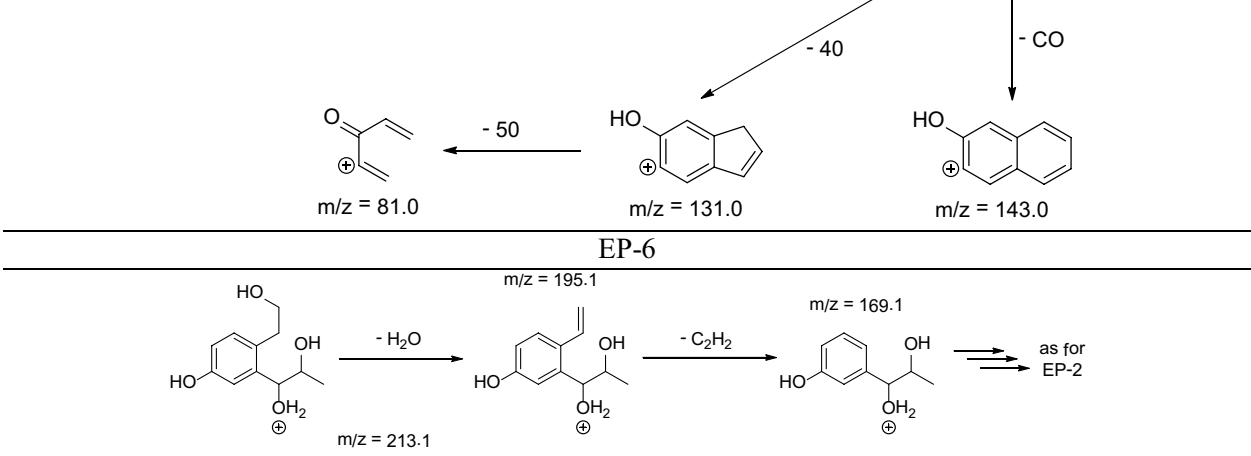

Acknowledgements Financial support for the present study was provided by UJ CM Grant number K/ZDS/007860.

\section{Compliance with ethical standards}

Conflict of interest The authors have no conflicts of interest to declare
Open Access This article is distributed under the terms of the Creative Commons Attribution 4.0 International License (http://creativeco mmons.org/licenses/by/4.0/), which permits unrestricted use, distribution, and reproduction in any medium, provided you give appropriate credit to the original author(s) and the source, provide a link to the Creative Commons license, and indicate if changes were made. 


\section{References}

Andaluri G, Suri RP, Kumar K (2013) Occurrence of estrogen hormones in biosolids, animal manure and mushroom compost. Environ Monit Assess 184:1197-1205

Anderson PD, Johnson AC, Pfeiffer D, Caldwel D, Hannah R, Mastrocco F, Sumpter J, Williams RJ (2012) Endocrine disruption due to estrogens derived from humans predicted to be low in the majority of US surface waters. Environ Toxicol Chem 31:1407-1415

Arnold KE, Brown AR, Ankley GT, Sumpter JP (2014) Medicating the environment: assessing risks of pharmaceuticals to wildlife and ecosystems. Phil Trans R Soc Lond B Biol Sci. https://doi. org/10.1098/rstb.2013.0569

Ashoka G, Geetha MS, Sullia SB (2002) Bioleaching of composite textile dye effluent using bacterial consortia. Asian J Microb Biotechnol Environ Sci 4:65-68

Avberšek M, Šömen J, Heath E (2011) Dynamics of steroid estrogen daily concentrations in hospital effluent and connected waste water treatment plant. J Environ Monit 13:2221-2226

Biswas S, Shapiro C, Kranz W, Mader T, Shelton D, Snow D, BarteltHunt S, Tarkalson D, van Donk S, Zhang T (2013) Current knowledge on the environmental fate, potential impact, and management of growth-promoting steroids used in the US beef cattle industry. J Soil Water Conserv 68:325-336

Braga KPBC (2011) Antimicrobial activity and mineral composition of Shiitake mushrooms cultivated on agricultural waste. Braz Arch Biol Technol 54:991-1002

Brennan PJ, Griffin PFS, Lösel DM, Tyrrell D (1975) The lipids of fungi. Prog Chem Fats Other Lipids 14:49-89

Cerniglia CE, Sutherland JB, Crow SA (1992) Fungal metabolism of aromatic hydrocarbons. In: Microbial degradation of natural products. VCH Press, Weinheim, pp 193-217

Cruz-Morató C, Lucas D, Llorca M, Rodriguez-Mozaz S, Gorga M, Petrovic M, Barceló D, Vicent T, Sarrà M, Marco-Urrea E (2014) Hospital wastewater treatment by fungal bioreactor: removal efficiency for pharmaceuticals and endocrine disruptor compounds. Sci Total Environ 15:365-376

Dąbrowska M, Muszyńska B, Starek M, Żmudzki P, Opoka W (2018) Degradation pathway of cephalosporin antibiotics by in vitro cultures of Lentinula edodes and Imleria badia. Int Biodeterior Biodegrad 127:104-112

El Osta R, Almont T, Diligent C, Hubert N, Eschwège P, Hubert J (2016) Anabolic steroids abuse and male infertility. Basic Clin Androl 26:2

Eldridge HC, Milliken A, Farmer C, Hampton A, Wendland N, Coward L, Gregory DJ, Johnson CM (2017) Efficient remediation of $17 \alpha$-ethynylestradiol by Lentinula edodes (shiitake) laccase. Biocatal Agric Biotechnol 10:64-68

Hofrichter M (2002) Review: lignin conversion by manganese peroxidase (MnP). Enzym Microb Tech 30:454-466

Hotchkiss AK, Rider CV, Blystone C, Wilson VS, Hartig PC, Ankley GT, Foster PM, Gray CL, Gray LE (2008) Fifteen years after "wingspread"-environmental endocrine disrupters and human and wildlife health: where we are today and where we need to go. Toxicol Sci 105:235-259

Ibarluzea JM, Fenanadez MF, Santa-Marina L, Olea-Serrano MF, Rivas MF, Aurrekoettxea JJ, Exposito J, Lorenzo M, Torne P, Villalobos M, Pedraza V, Sasco J, Olea N (2004) Breast cancer risk and the combined effect of environmental estrogens. Cancer Causes Control 15:591-600
Kirk TK, Farrell RL (1987) Enzymatic "combustion": the microbial degradation of lignin. Annu Rev Microbiol 41:465-505

Kryczyk A, Piotrowska J, Sito M, Sułkowska-Ziaja K, Dobosz K, Opoka W, Muszyńska B (2017) Remediation capacity of Cd and $\mathrm{Pb}$ ions by mycelia of Imleria badia, Laetiporus sulphureus and Agaricus bisporus in vitro culture. J Environ Sci Health B 52:617-622

Lang E, Eller I, Kleeberg R, Martens R, Zadrazil F (1995) Interaction of white rot fungi and microorganisms leading to biodegradation of soil pollutants. In: Proceedings of the 5th international FZK/ TNo conference on contaminated soil. Maustrient, pp 1277-1278

Liang J, Shang Y (2013) Estrogen and cancer. Ann Rev Physiol 75:225-240

Mansur M, Arias ME, Copa-Patino JL, Flardh M, Gonzalez AE (2003) The white rot fungus Pleurotus ostreatus secretes laccase isozymes with different substrate specificites. Mycologia 95:1013-1020

Mleczek M, Siwulski M, Rzymski P, Niedzielski P, Gąsecka M, Jasińska A, Budzyńska S, Budka A (2017) Multi-elemental analysis of Lentinula edodes mushrooms available in trade. J Environ Sci Health B 52:196-205

Moore SC, Matthews CE, Ou Shu X, Yu K, Gail MH, Xu X, Ji BT, Chow WH, Cai Q, Li H, Yang G, Ruggieri D, Boyd-Morin J, Rothman N, Hoover RN, Gao YT, Zheng W, Ziegler RG (2016) Endogenous estrogens, estrogen metabolites, and breast cancer risk in postmenopausal Chinese women. J Natl Cancer Inst 108:10

Muszyńska B, Sułkowska-Ziaja K, Ekiert H (2013) Analysis of indole compounds in methanolic extracts from the fruiting bodies of Cantharellus cibarius (the Chanterelle) and from the mycelium of this species cultured in vitro. J Food Sci Technol 50:1233-1237

Muszyńska B, Pazdur P, Lazur J, Sułkowska-Ziaja K (2017) Lentinula edodes (Shiitake)—biological activity. Med Inter Rev 108:189-195

Riggins A, Gregory DJ (2015) Degradation of $17 \alpha$-Ethynylestradiol (EE2) using laccases isolated from the white rot fungi Lentinula edodes, Trametes versicolor, and Agaricus bisporus. https://www. samford.edu/programs/undergraduate/researchexperience/files/ Research-Paper-Aarika-Riggins.pdf

Salla RF, Gamero FU, Rissoli RZ, Dal-Medico SE, Castanho LM, dos Santos Carvalho C, Silva-Zacarin EC, Kalinin AL, Abdalla FC, Costa MJ (2016) Impact of an environmental relevant concentration of $17 \alpha$-ethynylestradiol on the cardiac function of bullfrog tadpoles. Chemosphere 144:1862-1868

Sułkowska-Ziaja K, Muszyńska B, Szewczyk A (2015) Antioxidant components of selected indigenous edible mushrooms of the obsolete order Aphyllophorales. Rev Iberoam Micol 32:99-102

Sułkowska-Ziaja K, Szewczyk A, Gdula-Argasińska J, Ekiert H, Jaśkiewicz J, Muszyńska B (2016) Chemical compounds of extracts from Sarcodon imbricatus at optimized growth conditions. Acta Mycol 51:1-11

Taheran M, Brar SK, Verma M, Surampalli RY, Zhang TC, Valeroa JR (2016) Membrane processes for removal of pharmaceutically active compounds (PhACs) from water and wastewaters. Sci Total Environ 547:60-77

Wong DWS (2009) Structure and action mechanism of ligninolytic enzymes. Appl Biochem Biotechnol 157:174-209

Yuan JP, Kuang HC, Wang JH, Liu X (2008) Evaluation of ergosterol and its esters in the pileus, gill, and stipe tissues of agaric fungi and their relative changes in the comminuted fungal tissues. Appl Microbiol Biotechnol 80:459-465 